\title{
Originals
}

\section{Increase in Stable Glycosylated Haemoglobin After Induction of Poor Glycaemic Control}

\author{
S. Wettre ${ }^{1}$, H.J. Arnqvist ${ }^{1}$, G. Cederblad ${ }^{2}$ and G. Hermansson ${ }^{3}$ \\ Departments of ${ }^{1}$ Internal Medicine, ${ }^{2}$ Clinical Chemistry and ${ }^{3}$ Paediatrics, University Hospital, Linköping, Sweden
}

\begin{abstract}
Summary. Eight insulin-treated diabetic patients in good glycaemic control were studied as out-patients with frequent determinations of stable glycosylated haemoglobin $\left(\mathrm{HbA}_{1 \mathrm{c}}\right)$ before, during and after 1 week of induced poor glycaemic control. Stable $\mathrm{HbA}_{1 \mathrm{c}}$ was determined by cation exchange chromatography after elimination of the labile fraction by incubation in saline $(0.15 \mathrm{~mol} / \mathrm{l})$. The increase in mean blood glucose was significant on the first day of reduced insulin therapy and greatest after 1 week $(6.9 \pm 3.9 \mathrm{mmol} / 1$ above basal values). Stable $\mathrm{HbA}_{1 \mathrm{c}}$ increased significantly on day 7 of the reduced insulin treatment. The increase represented, on average,
\end{abstract}

$0.009 \%$ of total haemoglobin per $\mathrm{mmol} / \mathrm{l}$ increase in mean blood glucose per $24 \mathrm{~h}$ during the period of induced hyperglycaemia. After restoring insulin therapy, a significant decrease in blood glucose was achieved on day 1 and after 2 days, the blood glucose level was similar to before the study. There was no significant decrease in stable $\mathrm{HbA}_{1 \mathrm{c}}$ within the first 2 weeks of improved glycaemia.

Key words: Glycosylated haemoglobin, Type 1 diabetes, stable $\mathrm{HbA}_{1 \mathrm{c}}$, hyperglycaemia.
Glycosylated haemoglobin $\left(\mathrm{HbA}_{1}\right.$ or its main fraction $\mathrm{HbA}_{1 \mathrm{c}}$ ) is considered to reflect the integrated blood glucose concentration during the preceding 1-2 months [1, 2]. The relationship between changes in glycaemic control and $\mathrm{HbA}_{1}$ has not been well characterized in clinical practice. Recent studies have shown changes in $\mathrm{HbA}_{1}$ level to occur within hours of changes in blood glucose concentrations [3-5, 17].

Rapidly formed $\mathrm{HbA}_{1}$ is labile and can be removed by incubation of the erythrocytes in saline for a few hours $[4,5]$, by dialysis of haemolysates $[18,21]$ or by chemical means [19]. The influence of changes in blood glucose level hampers the value of $\mathrm{HbA}_{1}$ as an index of average glycaemia and therefore the labile fraction should be eliminated when the assay is used for this purpose $[4-6,20]$. The resulting stable fraction thus assayed is regarded chemically to be the ketoamine form [4].

There are only two clinical studies of the change in $\mathrm{HbA}_{1}$ during induced hyperglycaemia $[7,8]$. In one of these [7], the method used included the labile fraction, and in the other [8], two different methods were used and the change in $\mathrm{HbA}_{1}$ and other indices of glycaemic control were inconsistent.

In one clinical experiment the increase in stable $\mathrm{HbA}_{1 \mathrm{c}}$ was determined during $24 \mathrm{~h}$ of hyperglycaemia monitored by the 'artificial pancreas' (Biostator). The calculated average rate of increase was $0.006 \%$ of total haemoglobin per mmol/1 glucose per $24 \mathrm{~h}$ [11].

Most investigators propose determination of total $\mathrm{HbA}_{1}$ when column chromatography is used because the advantage of determining $\mathrm{HbA}_{\mathrm{cc}}$ is small considering the difficulties of $\mathrm{HbA}_{1 \mathrm{c}}$ assay with column chromatography $[9,10]$. However, when studying the kinetics of glycosylation and deglycosylation it is of interest to determine $\mathrm{HbA}_{1 \mathrm{c}}$, which is the principal glycosylated fraction.

The aim of this study was to investigate the rate of increase in stable $\mathrm{HbA}_{1 \mathrm{c}}$ during 1 week of poor glycaemic control.

\section{Patients and Methods}

\section{Patients}

Two female and six male insulin-treated diabetic patients were studied (Table 1). All were ambulant, none was obese and none had retinopathy, neuropathy or nephropathy. The patients had good glycaemic control as indicated by basal values of mean blood glucose and stable $\mathrm{HbA}_{1 \mathrm{c}}$ (Table 2). The protocol for this study was approved by the local Ethical Committee and informed consent was obtained from all patients. 
Table 1. Clinical details of patients studied

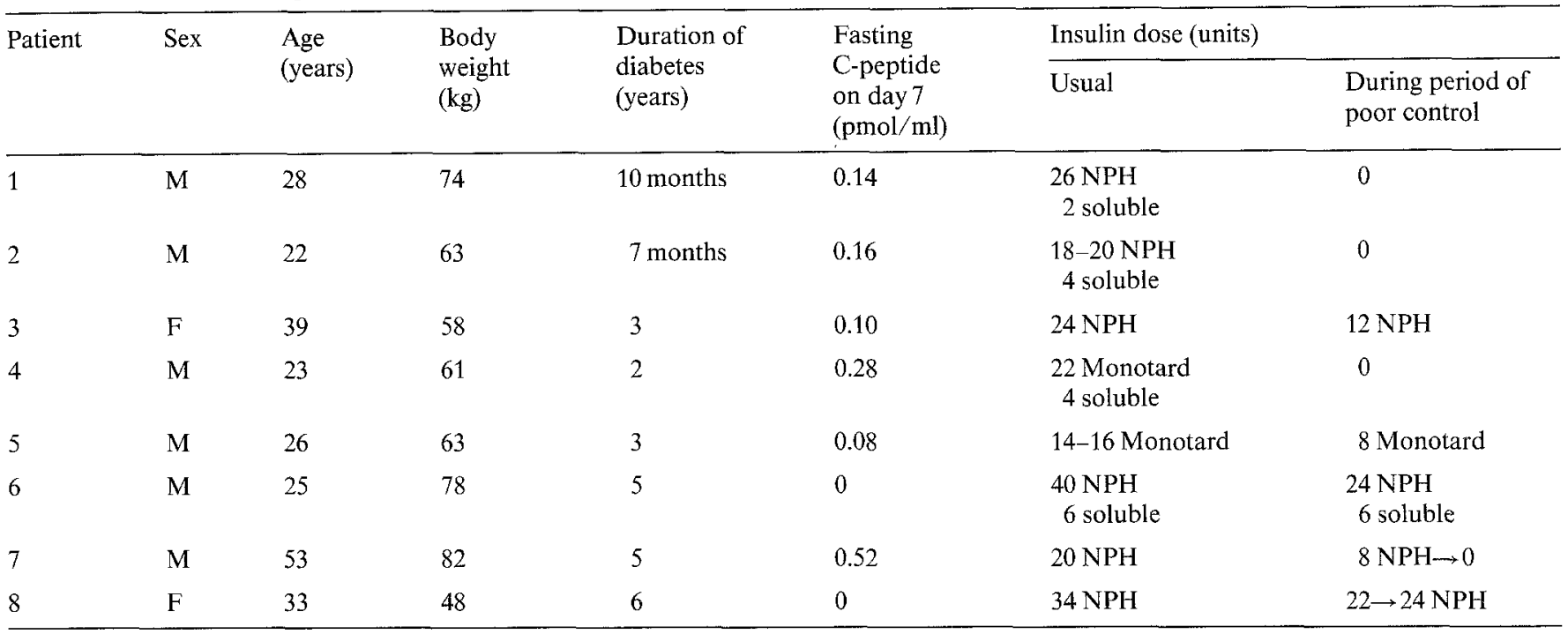

The study period consisted of 1 month during which the patients continued their normal daily activities. On testing days, they collected $24 \mathrm{~h}$ urine samples and measured their blood glucose themselves in the morning, before lunch, before dinner and at bed-time. The next morning after an overnight fast they came to the out-patient clinic between 07.00 and $08.00 \mathrm{~h}$ to deliver the blood glucose results and urine specimens and for blood sampling. During days 1-7, glycaemic control was assessed three times on three different days while the patients continued their usual treatment regime. During days $8-14$, insulin was reduced as indicated in Table 1 with no other changes in treatment. The intention of insulin reduction was to obtain a blood glucose concentration of approximately $15 \mathrm{mmol} / 1$ without ketosis. Plasma was also sampled for C-peptide determination (day 7). The patients visited the out-patient clinic daily except on days 13 and 14 (Saturday and Sunday) and they tested their urine daily for ketones. Insulin was increased on day 15 and during the last 2 weeks, glycaemic control was assessed four times. Fasting blood glucose and $\mathrm{HbA}_{1 \mathrm{c}}$ were taken at each visit to the out-patient clinic. On days 7, 14, 22 and 31, fasting blood was taken for haemoglobin, reticulocyte count and haptoglobin. Fasting samples were taken at the end of the day indicated.

\section{Methods}

The BM-Test-Glycemie 1-44 (Boehringer, Mannheim, FRG) was used for self-monitoring of blood glucose [12]. Whole blood and urinary glucose concentrations were measured by an automated hexokinase method. C-peptide was determined by radioimmunoassay (Novo, Copenhagen, Denmark).

Blood samples for measuring $\mathrm{HbA}_{1 \mathrm{c}}$, collected in tubes containing EDTA, were placed at $4{ }^{\circ} \mathrm{C}$ within $1 \mathrm{~h}$ and then washed and incubated on day 1 as described below. Haemolysates from day 10 were not prepared according to instructions and were excluded.

$\mathrm{HbA}_{1 \mathrm{c}}$ was determined with an ion exchange column method [14] modified from the reference method of Trivelli et al. [13] and from Gabbay et al. [2]. In this method the red cells are washed three times before haemolysis and chromatography. This step has been shown to eliminate part of the labile fraction [15]. In this study an incubation step was added to eliminate all the labile fraction. After washing in saline $(0.15 \mathrm{~mol} / \mathrm{l})$, the red cells were suspended overnight in saline at $37^{\circ} \mathrm{C}$ with glucose $(2 \mathrm{mmol} / 1)$ to prevent haemolysis. The low glucose concentration was shown in a preliminary experiment not to influence the results (not presented). The specimens were haemolysed according to Gabbay et al. [2] and stored in $-70^{\circ} \mathrm{C}$ until assayed 1-8 weeks later. All specimens were analysed twice with an interval of
1 month between the two runs and the means of the results were used. All specimens from one individual patient were assayed in the same run and one specimen each of high and low controls from frozen haemolysates were run in parallel. Inter-assay coefficient of variation during the study was $3.0 \%$ for the high and $6.6 \%$ for the low controls. Room temperature was $21.8 \pm 0.2^{\circ} \mathrm{C}$ (mean $\pm \mathrm{SD}$ ) (range $21.6-$ $22.0^{\circ} \mathrm{C}$ ) and buffer temperature $21.3 \pm 0.4^{\circ} \mathrm{C}$ (range $20.5-21.6^{\circ} \mathrm{C}$ ). Osmolality of the buffer was $99.3 \pm 5.0 \mathrm{mmol} / \mathrm{l}$ and its $\mathrm{pH}$ was kept within $\pm 0.02 . \mathrm{HbA}_{1 \mathrm{c}}$ obtained from 20 non-diabetic adults (non-incubated) was $6.1 \pm 1.4 \%$ (mean $\pm 2 \mathrm{SD}$ ). Statistical significance was assessed by Student's t-test for paired observations and by Wilcoxon's non-parametric test when indicated.

\section{Results}

All patients were able to adhere to the plan of the study. Table 2 shows the mean values of the variables analysed. There was a significant increase in mean blood glucose $(p<0.001)$, fasting blood glucose $(p<0.01)$ and urinary glucose (Wilcoxon $p<0.05$ ) on day 1 of the reduced insulin treatment. The maximal increase in mean blood glucose was $6.9 \pm 3.9 \mathrm{mmol} / \mathrm{l}$ (mean \pm SD) reached on day 7 of insulin reduction (day 14). The increase in fasting blood glucose was $4.9 \mathrm{mmol} / \mathrm{l}$, and for urinary glucose $363 \mathrm{mmol} / 24 \mathrm{~h}$.

Stable $\mathrm{HbA}_{1 \mathrm{c}}$ did not increase significantly during the first 4 days, but was increased after 1 week of reduced insulin $(p<0.05)$. The rate of increase in stable $\mathrm{HbA}_{1 \mathrm{c}}$ was calculated in relation to the increase in mean blood glucose in the individual patients. The mean of these values was $0.009 \%$ of total haemoglobin per $\mathrm{mmol} / 1$ glucose per $24 \mathrm{~h}$.

After restoring insulin therapy on day 15 , there was a significant decrease in mean blood glucose on the same day $(p<0.01)$ reaching the pre-study level after 2 days. At the end of the study, the mean blood glucose was lower than at the start $(p<0.05)$. Fasting blood glucose was decreased on day 3 of the increased insulin 
treatment $(p<0.005)$, urinary glucose on day 1 ( $p<$ 0.01 ) and did not differ from the pre-study values thereafter.

There was no significant decrease in stable $\mathrm{HbA}_{1 \mathrm{c}}$ during the 2 weeks of improved glycaemic control following the increase in insulin treatment.

The haemoglobin level was slightly but significantly decreased on days 14,17 and 31 compared with day 1 of the insulin reduction $(p<0.02, p<0.05, p<0.001$, respectively). There were no changes in reticulocyte counts or haptoglobin levels. Ketonuria $>2+$ was observed on one occasion in one patient.

\section{Discussion}

In this study the finding of a small increase in stable $\mathrm{HbA}_{1 \mathrm{c}}$ after 1 week in response to moderate hyperglycaemia and the average rate of increase related to the degree of hyperglycaemia support the original experimental results of Bunn et al. [16]. In that study, $\mathrm{HbA}_{1 \mathrm{c}}$ was determined with the reference cation exchange column chromatography measuring stable $\mathrm{HbA}_{1 \mathrm{c}}$ [13]. An increase was seen over 60 days and the average rate of increase was about $0.01 \%$ of total haemoglobin per $\mathrm{mmol} / \mathrm{l}$ glucose per $24 \mathrm{~h}$, similar to the rate of increase observed in the present clinical study $(0.009 \%)$.

When the kinetics of the ketoamine were investigated experimentally in vitro [22], the same rate of increase was obtained as in the original experiments in vivo [16]. A similar rate of increase of $\mathrm{HbA}_{1 c}$ has also been found in one clinical experiment in which hyperglycaemia was monitored with the 'Biostator' over $24 \mathrm{~h}$ [11]. The same rate of increase has been theoretically calculated on the predictions of the haemoglobin glycosylation as an irreversible first order reaction [23]. During the incubation of red cells in saline and high concentration glucose in vitro an increase in stable $\mathrm{HbA}_{1 \mathrm{c}}$ has been reported after $24 \mathrm{~h}$ but not after $2 \mathrm{~h}$ [4].

In 13 well controlled patients Boden et al. [7] found a significant increase in $\mathrm{HbA}_{1} 1$ week after the withdrawal of oral hypoglycaemic therapy. The increase in $\mathrm{HbA}_{1}$ was much greater than in the above mentioned experiments and in our study. In their study, the $\mathrm{HbA}_{1}$ method used also determined the labile fraction and this could explain the difference. In the same study the decrease in $\mathrm{HbA}_{1}$ after reinstitution of oral therapy was slower than the preceding increase.

In another study, we found a decrease within the first days of improved glycaemic control when $\mathrm{HbA}_{1 \mathrm{c}}$ was determined without the preceding elimination of the labile fraction [24]. In that study, the patients were newly diagnosed diabetic patients in poor glycaemic control and the initial values of $\mathrm{HbA}_{1 \mathrm{c}}$ were high. In this study, however, no significant decrease was observed when stable $\mathrm{HbA}_{1 \mathrm{c}}$ was determined during the first 14 days of improved glycaemic control. The pre-study level of stable $\mathrm{HbA}_{1 \mathrm{c}}$ was low and the increase during 
the short period of monitored hyperglycaemia was small. Under these conditions and the prediction that the glycosylation is irreversible, the decrease in stable $\mathrm{HbA}_{1 \mathrm{c}}$ within 2 weeks of good glycaemic control would be very small and hardly detectable.

The experimental circumstances in the study resemble common clinical situations of moderate temporary hyperglycaemia, which are thus able to generate small but significant and lasting increases in stable $\mathrm{HbA}_{1}$ levels.

Acknowledgement. The excellent technical assistance of Mrs. L. Lönnström is gratefully acknowledged. Financial support was given by the Swedish Diabetes Association, the Fund for Development and Research of the County Council of Östergötland and Linköpings Läkaresällskap.

\section{References}

1. Koening RJ, Peterson CM, Jones RL, Sudec C, Lehrman M, Cerami A (1976) Correlation of glucose regulation and haemoglobin $\mathrm{A}_{1 \mathrm{c}}$ in diabetes mellitus. N Engl J Med 295: 417-420

2. Gabbay KH, Hasty K, Breslow JL, Ellison RC, Bunn HF, Gallop PM (1977) Glycosylated haemoglobins and long term blood glucose control in diabetes mellitus. J Clin Endocr Metab 44: 859-864

3. Widness JA, Rogler-Brown TL, McCormick KL, Petzold KS, Susa J Jr, Schwartz HC (1980) Rapid fluctuations in glycohaemoglobin (haemoglobin $A_{1 c}$ ) related to acute changes in glucose. $J$ Lab Clin Med 95: 386-394

4. Svendsen PA, Christiansen JS, Søegaard V, Welinder BS, Nerup J (1980) Rapid change in chromatographically determined haemoglobin $A_{1 \mathrm{c}}$ induced by short-term changes in glucose concentration. Diabetologia 19: 130-136

5. Goldstein DE, Peth SB, England JD, Hess RL, Da Costa J (1980) Effects of acute changes in blood glucose on $\mathrm{HbA}_{1 c}$. Diabetes 29: $623-628$

6. Compagnucci P, Cartechini NG, Bolli G, de Feo P, Santeusanio F, Brunetti P (1981) The importance of determining irreversibly glycosylated hemoglobin in diabetes. Diabetes 30:607-612

7. Boden G, Master RW, Gordon SS, Shuman CR, Owen OE (1980) Monitoring metabolic control in diabetic out-patients with glycosylated hemoglobin. Ann Int Med 92:357-360

8. Brooks AP, Nairn IM, Baird JD (1980) Changes in glycosylated haemoglobin after poor control in insulin dependent diabetics. $\mathrm{Br}$ Med J 281: 707-710

9. Dunn PJ, Cole RA, Soeldner JS, Gleason RE, Kwa E, Firoosabadi H, Younger D, Graham CA (1979) Temporal relationship of glycosylated haemoglobin concentrations of glucose control in diabetes. Diabetologia 17: 213-220
10. James TM, Davis JE, McDonald JM, Santiago JV, Ladenson JH (1981) Comparison of hemoglobin $A_{1 c}$ and hemoglobin $A_{1}$ in diabetic patients. Clin Biochem 14: 25-27

11. Svendsen PA, Sandal-Christiansen J, Søegaard U, Nerup J (1981) Synthesis of glycosylated haemoglobin in vivo. Diabetologia 21: $549-553$

12. Fahlén M, Strömblad G, Lithner F (1980) Home monitoring of blood glucose without a photometer. Acta Endocr 94 (Suppl 238) $157-160$

13. Trivelli LS, Ranney HM, Lai H-T (1971) Hemoglobin components in patients with diabetes mellitus. New Engl J Med 284: 353

14. Arnqvist HJ, Cederblad G, Hermansson G, Ludvigsson J, Wettre S (1981) A chromatographic method for haemoglobin $A_{1}$ : comparison with two commercial kits. Ann Clin Biochem 18: 240-242

15. Wettre S, Arnqvist HJ, Cederblad G (1981) Time course of increase in glycosylated haemoglobin after induction of poor glucaemic control. Acta Endocr 98 (Suppl 245) 90

16. Bunn HF, Haney DN, Kamin S, Gabbay KH, Gallop PM (1976) The biosynthesis of human hemoglobin $A_{1 c} . J$ Clin Invest 57 : 1652-1659

17. Spicer KM, Allen RC, Hallet D, Buse MG (1979) Synthesis of hemoglobin $A_{1 c}$ and related minor hemoglobins by erythrocytes. $\mathbf{J}$ Clin Invest $64: 40-48$

18. Ditzel J, Forsham PH, Lorenzi M (1980) Rapid fluctuations in glycosylated haemoglobin as related to acute changes in blood glucose. Diabetologia 19: 403-404 (Letter)

19. Nathan DM, Avezzano ES, Palmer JL (1981) A rapid chemical means for removing labile glycohemoglobin. Diabetes 30:700701

20. Bolli G, Compagnuzzi P, Cartechini MG, De Feo P, Santeusanio F, Brunetti P (1980) Analysis of short-term changes in reversibly and irreversibly glycosylated haemoglobin $A_{1}$ : relevance to diabetes mellitus. Diabetologia 21: 70-72

21. Ditzel J, Kjaergaard JJ, Kawahara R, Østergaard GZ, Mouritz-Andersen $T$ (1981) Glycosylated hemoglobin in relation to rapid fluctuations in blood glucose in children with insulin-dependent diabetes: a comparison of methods with and without prior dialysis. Diabetes Care 4: 551-555

22. Higgins PJ, Bunn HF (1981) Kinetic analysis of the non-enzymatic glycosylation of hemoglobin. J Biol Chem 256: 5204-5208

23. Beach KW (1979) A theoretical model to predict the behavior of glycosylated hemoglobin levels. J Theor Biol 82: 547-561

24. Arnqvist HJ, Cederblad G, Hermansson $G$, Ludvigsson J, Wettre $S$ (1982) Rapid and slow rate of decrease in $\mathrm{HbA}_{1 \mathrm{a}+\mathrm{b}}$ and $\mathrm{HbA}_{1 \mathrm{c}}$ during improved glycaemic control. Scand J Clin Lab Invest 42: 265-271

Received: 17 August 1981

and in revised form: 4 October 1982

Dr. S. Wettre

Department of Internal Medicine

Regionsjukhuset

S-58185 Linköping

Sweden 